\title{
Can psychological factors help us to determine adherence to CPAP? A prospective study
}

\author{
M.R. Wild*, H.M. Engleman\#, N.J. Douglas\#, C.A. Espie*
}

Can psychological factors help us to determine adherence to CPAP? A prospective study. M.R. Wild, H.M. Engleman, N.J. Douglas, C.A. Espie. (C)ERS Journals Ltd 2004.

ABSTRACT: The present study objective was to establish whether pretreatment social cognitive variables may contribute to the explanation of variance in adherence to continuous positive airway pressure (CPAP) treatment for patients with obstructive sleep apnoea/hypopnoea syndrome (OSAHS).

A total of 119 of 180 consecutive OSAHS patients were recruited to the study prior to initial CPAP titration. Patients completed psychological measures of health value, health locus of control (incorporating internality, chance, powerful others) and selfefficacy prior to CPAP titration. Objective adherence data were measured by CPAP unit time clocks and collected at 3-month follow-up. Average nightly use was calculated over this period.

Logistic regression of prospective predictors of adherence produced a model comprising psychological (health value, internality, powerful others), as well as clinical variables (Epworth score, body mass index, apnoea/hypopnoea index, CPAP pressure). This model explained $24 \%$ of the variance in CPAP use, and correctly identified $75 \%$ of adherers and $53 \%$ of nonadherers.

Although the psychological variables explained only a small amount of the overall variance in adherence behaviour, this result provides further support for the hypothesis that psychological variables contribute, in part, to continuous positive airway pressure adherence. Future research should focus on highlighting discrete variables, which may helpfully inform psychologically based interventions aimed at improving the use of continuous positive airway pressure by patients with obstructive sleep apnoea/ hypopnoea syndrome at risk of discontinuance.

Eur Respir J 2004; 24: 461-465.
*Section of Psychological Medicine, University of Glasgow, and ${ }^{\#}$ Edinburgh Sleep Centre, Dept of Respiratory Medicine, University of Edinburgh, UK

Correspondence: M. Wild

Section of Psychological Medicine

Academic Centre

Gartnavel Royal Hospital

1055 Great Western Road

Glasgow

G12 0XH

UK

Fax: 441413574899

E-mail: m.wild@clinmed.gla.ac.uk

Keywords: Patient compliance positive pressure ventilation sleep apnoea syndromes

Received: October 142003

Accepted after revision: April 262004
Obstructive sleep apnoea/hypopnoea syndrome (OSAHS) occurs in $2-4 \%$ of the middle-aged population [1]. Effective treatment for OSAHS can be achieved through the use of continuous positive airway pressure (CPAP). Continued adherent use of CPAP is required to prevent the redevelopment of symptoms such as excessive daytime sleepiness, cognitive impairment and disturbance of mood [2-5] and effective use is associated also with reduced road traffic incident rates $[6,7]$ and reduced blood pressure $[8,9]$.

CPAP, unlike pharmacological treatments for other chronic conditions, is a relatively cumbersome treatment that requires considerable behavioural change and commitment to adherent use for it to remain clinically effective. Rates of initial acceptance and ongoing adherence to CPAP treatment appear consistently suboptimal across international OSAHS case series, with $\sim 18 \%$ of patients recommended for CPAP declining to take this home, and up to $30 \%$ of initial acceptors having abandoned CPAP by 5 yrs [10]. With increasing robust evidence for the benefits of CPAP treatment [2-9] and a scarcity of effective therapeutic alternatives in patients with severe OSAHS, patients' problems in using CPAP are an important clinical and research issue.

The determinants of patients' use of CPAP have been the focus of previous literature, in case series correlating clinical variables, such as initial disease severity and treatment sideeffects with CPAP usage [2, 11-18]. Significant correlations between clinical predictors and CPAP adherence, when present, tend to be weak in magnitude and thus of limited predictive power in the clinical setting.

Patients' adherence behaviour to CPAP, as in other difficult treatment regimes, is likely to be modified by psychological as well as demographic and physiological variables. Social cognition models advocate that cognitive variables (i.e. beliefs held by an individual about, for instance, their ability to solve problems) are primary determinants of individual social behaviours [19]. They assume that these behaviours are based on elaborate, but subjective, cost-benefit analysis of the most likely outcome of differing courses of action. Such models have been successfully adapted and applied to health care settings. There, they have made a valuable contribution to the understanding of which patients will reliably perform health behaviours [20], such as adhere to a recommended diabetic regimen [21]. Research evidence of psychological determinants of CPAP adherence behaviour remains limited, though claustrophobic reactions [2], depressive and hypochondriacal personality traits [22], and referral initiated by the partner rather than the patient [23] have each been associated with poor CPAP use. More recently studies have implicated the role of specific psychological variables in the prediction of adherence to CPAP [24, 25].

The present study applied a social cognition model [26] to a population of patients with OSAHS prior to initiation of 
CPAP therapy, in order to investigate whether psychological factors may usefully contribute to the prediction of subsequent adherence to this form of treatment. Wallston's model [26] includes the psychological constructs of health value, health locus of control (incorporating the subscales of internality, powerful others and chance) and self-efficacy. Health value reflects the importance an individual places on maintaining good physical health. Internality is the extent to which an individual believes that they are responsible for their own health and illness. Powerful others relates to beliefs that health is determined by powerful others (e.g. sleep physicians). Chance measures the extent to which health and illness are believed to be a matter of fate or luck. Self-efficacy refers to an individuals belief in their capability to organise and carry out the courses of action required to deal with prospective situations.

In addition, demographic and clinical data were considered as possible predictors. These variables were included so as to take account of previous research evidence highlighting their potentially important contribution to the prediction of adherence and also to avoid an unnecessary and potentially less environmentally valid focus on purely psychological factors.

\section{Material and methods}

\section{Patients and procedures}

The present study population was a prospective, consecutive series of patients attending for overnight CPAP titration at the Edinburgh Sleep Centre over an 8-month period. All had been diagnosed with OSAHS following polysomnographic monitoring in the home or in the laboratory and been recommended for CPAP treatment. CPAP titration patients were excluded from the study only if suffering serious coincident illness or already participating in another research protocol. Following consent, eligible patients were asked to complete a two-page psychological questionnaire during the evening before their CPAP titration. Therefore, these measures were obtained before patients had nocturnal experience of CPAP.

Patients received a standard care package during diagnosis, treatment and follow-up [23]. This included a daytime education, mask fitting and CPAP familiarisation session delivered by experienced nursing staff on a day prior to the CPAP titration. CPAP titration was performed in the laboratory using auto-adjusting CPAP units (Autoset ${ }^{\mathrm{TM}}$, ResMed Ltd, Abingdon, UK), and patients were allowed home the next morning with a fixed CPAP unit typically set at the 95th percentile of the auto-adjusting pressure-delivery profile. Post-treatment support was freely available through telephone calls or visits to nursing staff, and patients were telephoned by staff at 2 weeks to check progress and offer any interventions necessary. Formal follow-up was conducted through medical outpatient review at 3 months.

\section{Study measures}

Psychological measures. Three psychological measures were used in accordance with Wallston's modified learning theory [26].

The multidimensional locus of control scale. This scale [27] provides a measure of generalised expectancy beliefs in relation to health along three dimensions, comprising internality (i.e. measuring the extent to which an individual believes the locus of control is internal), chance (i.e. measuring the belief in chance or external factors in determining health outcomes) and powerful others (i.e. measuring the belief in the control over an individual's health by powerful others, particularly health professionals). Patients were asked to rate, on a scale of 1 (strongly disagree) to 6 (strongly agree), to what extent they agreed or disagreed with 18 health-related belief statements. Alpha reliability for each of the scales has been reported to range from $0.67-0.77$.

The health value scale. This scale [28] provides a general measure of the value an individual places on their health. Patients were required to indicate, along a scale of 1 (strongly agree) to 7 (strongly disagree), how much they agreed or disagreed with 4 health value belief statements. The internal consistency of this scale is 0.67 (Cronbach's alpha).

The generalised self-efficacy scale. This scale [29] assesses the strength of an individual's belief in their ability to respond to novel or difficult situations and to deal with any associated obstacles or setbacks. Patients were asked to indicate how true they believed 10 generalised self-efficacy statements to be, in relation to themselves, along a scale of 1 (not at all true) to 4 (exactly true). The alpha reliability of this scale ranges $0.82-0.93$.

Clinical variables. Clinical variables were collected from case notes and questionnaires completed during diagnosis. These comprised pretreatment demographic variables (age, sex, body mass index (BMI), reported alcohol intake and current cigarette smoking status), apnoea/hypopnoea index (AHI) and minimal oxygen saturation during diagnostic polysomnography, Epworth score [30] at diagnosis, and the pressure at which CPAP treatment was issued after titration.

CPAP adherence. Use of CPAP was measured objectively by integral time clocks contained within CPAP units, logging cumulative time that units were switched on. Time clocks were read at the 3-month outpatient follow-up appointment and the average nightly CPAP on-time calculated (h per night). Patients who failed to attend for follow-up were telephoned for time clock readings.

\section{Data analysis}

Clinical and demographic variables for this sample were compared by Chi-squared and unpaired t-tests with those of a previous large sample from the same site [15]. These analyses were also applied to investigate potential between group differences relating to adherence and nonadherence in accordance with Wallston's model [26].

The relationship between putative predictive variables and subsequent adherence was assessed using logistic regression. Such analysis aims to predict the membership of a categorical dependent variable (in this case, adherent/nonadherent, as this is the most clinically relevant variable) on the basis of categorical or continuous independent variables. For the dependent variable of average CPAP adherence, a cut-off point to divide lower from higher adherers was set, a priori, at $3 \mathrm{~h}$ per night. This value corresponds with the mean level of clinically effective adherence found in local prospective patient samples [4, 23].

Psychological and clinical variables were entered as continuous or categorical covariates as appropriate in a forward stepwise regression, using liberal inclusion $(\mathrm{p}<0.2)$ and exclusion criteria $(\mathrm{p}>0.3)$ to avoid type II errors resulting from colinearity [31]. 
A directly comparable study on which to base a power calculation to determine the required sample size was not found within the OSAHS or CPAP literature. However, by extracting data from similar research examining adherence issues in diabetes [32], a power calculation indicated that 40 subjects per group (group 1, adherent subjects; group 2, nonadherent subjects; total $=80$ ) would be necessary to demonstrate a significant difference between the groups $(\mathrm{p}<0.05)$ using an unpaired one-tailed independent samples t-test with a power of 0.8 .

\section{Results}

Of 180 eligible patients, 162 patients consented to participate in the study and were given the psychological questionnaires. Of these, 119 completed all questionnaire items and were thus suitable for analysis. Thus participation rate in this consecutive series was $90 \%$ and the analysis rate was $73 \%$. The 119 analysed patients $(79 \%$ male, $82 \%$ married, $77 \%$ in paid employment, $56 \%$ current cigarette smokers) had a mean age \pm SD of $51 \pm 11$ yrs. Further clinical descriptive data of the study population are provided in table 1 . There were no significant differences in demographic and clinical variables between this sample and the previous cross-sectional cohort [15] from the same centre.

At 3-month follow-up, mean CPAP use in this prospective sample averaged $3.6 \pm 2.7 \mathrm{~h}$ per night. Altogether, 21 participants $(18 \%)$ had received technological interventions for CPAP related side-effects (e.g. mask change, addition of chin strap, decongestant medication).

To investigate the potential predictive utility of Wallston's model [26] a median split was used to establish a cut-off point for the psychological variables. Using these cut-offs, subjects were then categorised, in accordance with Wallston's [26] model, as adherent or nonadherent on the basis of their psychological profile. No significant difference between these two groups was observed on the basis of adherence data.

Logistic regression analysis (table 2) constructed a sevenvariable model comprising the clinical variables of Epworth score, AHI, BMI and CPAP pressure and psychological variables of internality, powerful others and health value, together explaining $24 \%$ of variance in adherence to CPAP. Higher adherence status was significantly and independently associated with greater disease severity (Epworth and AHI), BMI, lower prescribed CPAP pressure, stronger internal locus of control, less belief in powerful others and greater health value. Putative predictive variables rejected by the analysis included age, current smoking habit, marital status, alcohol consumption, minimal oxygen saturation, chance and self-efficacy.

A comparative regression excluding psychological covariates (table 2) produced identical clinical predictors, but explained $6 \%$ less variance in CPAP use.

Table 1.-Summary clinical profile of study population

Variable

\begin{tabular}{lc}
\hline BMI kg $\cdot \mathrm{m}^{-2}$ & $33 \pm 7$ \\
AHI events $\cdot \mathrm{h}^{-1}$ & $45 \pm 35$ \\
CPAP pressure $\mathrm{cmH}_{2} \mathrm{O}$ & $9 \pm 2$ \\
Min $S \mathrm{a}, \mathrm{O}_{2} \%$ & $80 \pm 10$ \\
Epworth score & $13 \pm 5$ \\
Use of alcohol units $\cdot$ week $^{-1}$ & $8 \pm 11$ \\
\hline
\end{tabular}

Data are presented as mean \pm SD. BMI: body mass index; AHI: apnoea hypopnoea index; CPAP: continuous positive airway pressure; Min $\mathrm{Sa}, \mathrm{O}_{2}$ : minimum blood oxygen saturation. $\mathrm{n}=119$.
Table 2. - Results of forward logistic regression analysis for the models of determinants including and excluding psychological variables

$\operatorname{Exp}(\mathrm{B}) \quad \mathrm{p}$-value

\begin{tabular}{lll}
\hline Including psychological variables & & \\
AHI & 1.019 & 0.019 \\
CPAP pressure & 0.802 & 0.037 \\
BMI & 1.103 & 0.007 \\
Epworth score & 1.127 & 0.011 \\
Internality & 1.064 & 0.119 \\
Powerful others & 0.946 & 0.162 \\
Health value & 1.396 & 0.019 \\
Excluding psychological variables & & \\
AHI & 1.02 & 0.018 \\
CPAP pressure & 0.82 & 0.051 \\
BMI & 1.09 & 0.016 \\
Epworth Score & 1.09 & 0.036 \\
\hline
\end{tabular}

Including psychological variables: Nagelkerke $R^{2}=0.24$. Excluding psychological variables: Nagelkerke $R^{2}=0.18$. $\operatorname{Exp}(\mathrm{B})$ : exponential beta; AHI: apnoea hypopnoea index; CPAP: continuous positive airway pressure; BMI: body mass index.

\section{Discussion}

The current prospective study of CPAP use shows that the social cognitive variables of health value, internal locus of control, and powerful others are implicated in the prediction of adherence to this treatment, in addition to clinical variables (i.e. Epworth score, BMI, AHI, CPAP pressure) already identified $[10,12,15]$. However, only health value contributed significantly to the explanation of variance.

These findings on psychological associates of CPAP use complement those of EDINGER et al. [22], who found that $62 \%$ of the total variance in adherence to CPAP was explained by a combination of high scores on hypochondriasis and depression scales from the Minnesota Multiphasic Personality Inventory, high values of BMI and high ratings of subjective daytime sleepiness. Hypochondriasis (i.e. over-concern with one's health) would seem to suggest the presence of high health value, a trait found to be predictive of adherent behaviour in the current study population. Although, EDINGER et al. [22] explained $62 \%$ of the variance in CPAP use in their study population, this is not an entirely comparable study as their sample size was small $(n=28)$ and comprised male veterans.

In addition to high health value, other psychological constructs associated with higher adherence status were higher internal locus of control and lower powerful others scores. Those who hold such beliefs consider more strongly that they have significant control over their own circumstances and environment. In line with this, they would be more likely to internalise advice given to them by sleep physicians and persist with CPAP use, despite inconveniences or adverse side-effects. This finding is congruent with the results of HoY et al. [23], which suggested that adherers were more likely to self-refer for treatment. This describes the action of an individual who believes in their ability to control their own environment. Also, the presented results support the findings of STEPNOWSKY et al. [25], who reported that CPAP users who engaged in active coping strategies in demanding situations reflected greater levels of use. These users appear to show greater independence in their selfmanagement, again a feature of those with higher levels of internal locus of control who are less influenced by powerful others. However, it must be noted that these variables, although appearing in the final model, did not contribute significantly to the explanation of variance in adherence 
behaviour. Of course it is likely that psychological variables other than those examined in the current study are implicated in the CPAP use. This has indeed been supported [24, 25]. However, a wider array of psychological measures were not included in the study as it was the intention to evaluate the utility of a coherent and concise model, rather than simply a variety of psychosocial variables. This was felt to be more likely to lead to the development of psychologically informed interventions aimed at improving CPAP use.

In terms of clinical variables, greater disease severity and poorer general health (i.e. greater subjective sleepiness, AHI, $\mathrm{BMI})$ predict greater levels of adherence, as does greater nocturnal mask comfort (i.e. lower CPAP pressure). Again, such a profile supports the inclusion of health value in the predictive model, as those who adhere to CPAP seem to acknowledge the serious nature of their physical condition and take steps to address the more controllable aspects of their health-related difficulties.

Potential criticisms of the current study include a possible sampling bias resulting from the relatively low analysis rate $(73 \%)$. However, this was largely due to incomplete questionnaire responses and not to missing adherence data. Furthermore, the study sample was similar to another study sample recruited from the same centre [15]. Thus, it is unlikely that any significant sampling bias exists within the study sample. Another potential criticism is the use of telephone time clock readings. This could have resulted in the collection of erroneous adherence data. However, this method of collection was used in only 19 cases and, in all but one case, the adherence data made clinical sense, suggesting that these patients had provided truthful data. One case was removed from the analysis as it suggested a clinically unlikely rate of nightly adherence. Regarding analysis, the authors decided to dichotomise the dependent variable of adherence. Greater than $3 \mathrm{~h}$ use per night has been shown in local samples to be the lowest level of use to ensure clinical improvement in symptoms [4, 23]. Through this, some explanatory variance may have been lost. However, by splitting this variable and analysing data on the basis of adherence and nonadherence the clinical significance and utility of the results was enhanced. Finally, time clock readings measured machinerun time, rather than machine-run time at set pressure, potentially allowing patients to present inaccurate adherence readings. That said, as mentioned above, the average adherence rate in this population was similar to another sample studied at the same centre [15], and the only clinically unrealistic outlier was identified and removed.

Disease-specific psychological measures were not used in the current study, although it has been suggested that generalised measures may be less sensitive to the cognitive processes underlying health behaviour. Indeed, since the completion of this study, a psychometric measure based on the self-efficacy construct has been validated for use in the OSAHS population [33]. However, at the time of investigation it seemed more appropriate to evaluate the validity of the generalisable psychological model before addressing disease or treatment specific aspects.

Research investigating determinants of CPAP reflects a pattern of development similar to that of adherence research across other clinical pathologies and healthcare systems [34, 35]. Early attempts to explain patterns of adherence focussed on sociodemographic and clinical variables. Latterly, behavioural and psychosocial variables have been evaluated as potential contributors to the explanation of adherence patterns. Most recently, and most productively, attempts have been made to integrate these approaches. The current study lends weight to the thesis that psychosocial variables are an important factor to consider when investigating CPAP adherence. A considerable amount of research has evaluated the role of biomedical determinants. It is now important to understand more about which psychosocial variables impact on eventual CPAP use.

Although the implicated psychological variables explained only a small amount of variance in adherence behaviour, overall, the present authors suggest that these results provide further evidence that psychological factors contribute to CPAP adherence. They suggest that cognitive constructs and beliefs are involved in the motivation to adhere to CPAP. These constructs have been found to be useful predictors of health behaviours central to the management of other chronic illness. They are not believed to be stable personality traits, but can and do change over time as a consequence of intervening experiences, such as ill-health $[26,28]$. Therefore, research focussing on modifiable, cognitive variables would appear to be a more productive seam of investigation, in terms of developing therapeutic interventions, than studies evaluating the contribution of socio-demographic or more persistent personality variables that are less amenable to change. Although, previous studies have demonstrated that adherence to CPAP can be improved through interventions such as intense clinical support [23] and group education [36], these studies were not psychologically informed and the mechanism of change was not systematically evaluated.

It is clear that, clinically, these results are not a direct step towards the development of a specific psychosocial intervention. However, they do highlight the potential contribution of social cognitive factors and suggest that future research should aim to more accurately describe other potentially implicated psychological variables, through the consideration of wider theory (e.g. family-based factors, staff-patient relationships) and methodology (e.g. qualitative studies, experimental paradigms).

\section{References}

1. Young T, Palta M, Dempsey J, Skatrud J, Weber S, Bader S. The occurrence of sleep-disordered breathing among middleaged adults. New Engl J Med 1993; 328: 1230-1235.

2. Kribbs NB, Pack AI, Kline LR, et al. Objective measurement of patterns of nasal CPAP use by patients with obstructive sleep apnea. Am Rev Respir Dis 1993; 147: 887-895.

3. Douglas NJ. Systematic review of the efficacy of CPAP. Thorax 1998; 53: 414 415.

4. Engleman HM, Kingshott RN, Wraith PK, Mackay TW, Deary IJ, Douglas NJ. Randomized placebo-controlled crossover trial of CPAP for mild sleep apnea/hypopnea syndrome. Am J Respir Crit Care Med 1999; 159: 461-467.

5. Jenkinson C, Davies RJ, Mullins R, Stradling JR. Comparison of therapeutic and subtherapeutic nasal continuous positive airway pressure for obstructive sleep apnoea: a randomised prospective parallel trial. Lancet 1999; 353: 2100-2105.

6. George CF, Nickerson PW, Hanly PJ, Miller TW, Kryger MH. Sleep apnea patients have more automobile accidents. Lancet 1987; 2: 447.

7. Krieger $\mathrm{J}$, Meslier $\mathrm{N}$, Lebrun $\mathrm{T}$, et al. Accidents in obstructive sleep apnea patients treated with nasal continuous positive airway pressure; a prospective study. Chest 1997; 112: 1561-1566.

8. Faccenda JF, Mackay TW, Boon NA, Douglas NJ. Randomized placebo-controlled trial of continuous positive airway pressure on blood pressure in the sleep apneahypopnea syndrome. Am J Respir Crit Care Med 2001; 163: 344-348.

9. Pepperell JC, Ramdassingh-Dow S, Crosthwaite $\mathrm{N}$, et al. Ambulatory blood pressure after therapeutic and subtherapeutic nasal continuous positive airway pressure for 
obstructive sleep apnoea: a randomised parallel trial. Lancet 2002; 359: 204-210.

10. Engleman HM, Wild MR. Improving CPAP use by patients with the sleep apnoea/hypopnoea syndrome (SAHS). Sleep Medicine Reviews 2003; 7: 81-99.

11. Hoffstein V, Viner S, Mateika A, Conway J. Treatment of obstructive sleep apnea with nasal continuous positive airway pressure: patient compliance, perception of benefits, and side effects. Am Rev Respir Dis 1992; 145: 841-845.

12. Meurice J, Dore P, Paquereau J, et al. Predictive factors of long-term compliance with nasal continuous positive airway pressure treatment in sleep apnea syndrome. Chest 1994; 105 : 429-433.

13. Rauscher H, Popp W, Wanke T, Zwick H. Acceptance of CPAP therapy for sleep apnea. Chest 1991; 100: 10191023.

14. Reeves-Hoche MK, Meck R, Zwillich CW. Nasal CPAP: an objective evaluation of patient compliance. Am J Respir Crit Care Med 1994; 149: 149-154.

15. McArdle N, Devereux G, Heidarnejad H, Engleman HM, Mackay TM, Douglas NJ. Long-term use of CPAP therapy for sleep apnea/hypopnea syndrome. Am J Respir Crit Care Med 1999; 159: 1108-1114.

16. Engleman HM, Martin SE, Douglas NJ. Compliance with CPAP therapy in patients with sleep apnoea/hypopnoea syndrome. Thorax 1994; 49: 263-266.

17. Rauscher H, Formanek D, Popp W, Zwick H. Self-reported vs measured compliance with nasal CPAP for obstructive sleep apnea. Chest 1993; 103: 1675-1680.

18. Fletcher EC, Luckett RA. The effects of positive reinforcement on hourly compliance in nasal continuous positive airway pressure users with obstructive sleep apnea. Am Rev Respir Dis 1991; 143: 936-941.

19. Conner M, Norman P. Health behaviour. In: Bellack AS, Hersen M, eds. Comprehensive Clinical Psychology. Johnson DW, Johnson M, eds., New York, Pergamon. Health Psychology 1998; Vol. 8, pp. 1-37.

20. Marteau TM. Health beliefs and attributions. In: Broome AK, ed. Health psychology: processes and applications. London, Chapman Hall, 1995; pp. 1-23.

21. Tillotson LM, Smith MS. Locus of control, social support, and adherence to the diabetic regimen. Diabetes Educ 1996; 22: $133-139$.

22. Edinger JD, Carwile S, Miller P, Hope V, Mayti C. Psychological status, syndromatic measures, and compliance with nasal CPAP therapy for sleep apnea. Percept Mot Skills 1994; 78: 1116-1118.

23. Hoy CJ, Vennelle M, Kingshott RN, Engleman HM, Douglas NJ. Can intensive support improve continuous positive airway pressure use in patients with sleep apnea/ hypopnea syndrome? Am J Respir Crit Care Med 1999; 59: 1096-1100.

24. Stepnowski CJ, Marler MR, Ancoli-Israel S. Determinants of nasal CPAP compliance. Sleep Medicine 2002; 3: 239-247.

25. Stepnowski CJ, Bardwell WA, Moore PJ, Ancoli-Israel S, Dimsdale JE. Psychologic correlates of compliance with continuous positive airway pressure. Sleep 2002; 7: 758-762.

26. Wallston KA. Hocus-pocus, the focus isn't strictly on the locus: Rotter's social learning theory modified for health. Cog Ther Res 1992; 16: 251-252.

27. Wallston KA, Wallston BA, De Vellis R. Development of the multidimensional health locus of control (MHLC) scales. Health Educ Monogr 1978; 6: 161-170.

28. Lau RR, Hartman KA, Ware JE. Health as a value: methodological and theoretical considerations. Health Psychol 1986; 5: 25-43.

29. Schwarzer R, ed. Self-efficacy: thought control of action. Washington DC, Hemisphere, 1992.

30. Johns MW. A new method for measuring daytime sleepiness: the Epworth sleepiness scale. Sleep 1991; 14: 540-545.

31. Hosmer D, Lemeshow S. Model building strategies and methods for logistic regression. In: Applied logistic regression. New York, Wiley, 1989; pp. 91-142.

32. Kavanagh DJ, Gooley S, Wilson PH. Prediction of adherence and control in diabetes. J Behav Med 1993; 16: 509-522.

33. Weaver TE, Maislin G, Dinges DF, et al. Self-efficacy in sleep apnea: instrument development and patient perceptions of obstructive sleep apnea risk, treatment benefit, and volition to use continuous positive airway pressure. Sleep 2003; 26: 727-732.

34. Lutfey KE, Wishner WJ. Beyond 'compliance' is 'adherence'. Improving the prospect of diabetes care. Diabetes Care 1999; 22: 635-639.

35. Vermeire E, Hearnshaw H, Van Royen P, Denekens J. Patient adherence to treatment: three decades of research. A comprehensive review. J Clin Pharm Ther 2001; 26: 331-342.

36. Likar LL, Panciera TM, Erickson AD, Rounds S. Group education sessions and compliance with nasal CPAP therapy. Chest 1997; 111: 1273-1277. 